\title{
Public Transportation Improvement Validation Model for Metropolitan City Karachi
}

\author{
Zubair Iqbal Rao ${ }^{a}$, Kamran Khan ${ }^{b}$, Syed Faraz Jafri ${ }^{c}$, and Khawaja Sheeraz ${ }^{d}$ \\ Department of Civil Engineering, Sir Syed University of Engineering and Technology, Karachi, Pakistan \\ E-mail: aengr_zubairrao@hotmail.com (Corresponding author), bkamran_khan85@hotmail.com , \\ cengr_sfjafri@hotmail.com, dkhawajasheeraz@gmail.com
}

\begin{abstract}
Any metropolitan city is identified by its effective operational transportation modes. In between that, public transportation plays vital role for getting the proper scale of the economy and in all aspects. Lesser the rate of vehicle ownership increases the improvement rate in public transport system. But the system should be linked with the effective controlled strategy that resembles with the meaningful and user friendly environment. Choice of mode of transport is selected by the road user which in turn dependent on the facilities provided in the passenger cars. Unfortunately the system of public transportation is diversified due to number of reasons. This not only predominates the Enforcement action but transforms the Engineering measures as well. According to the survey, more than $80 \%$ road users are the direct passengers of Buses and Mini buses. Not only that, they are forced to use more than two vehicles during the whole day for their complete trip accommodation. Apart from that, users are not satisfied with the existing network due to several reasons. These include improper route network, illegal work imposition, imbalanced fare collection, adverse vehicle condition, lack of Engineering and Enforcement measures etc.

This paper focuses on the main legendary actions and validation model that need to be adopted by concerned stakeholders for the enhanced public transportation system. For the sake of reason, a detailed public opinion survey has been done in which number of associated matters is discussed and recommendations are formulated based on the analyzed results in the paper. The thematic idea of the paper also covers the balanced between the improvement in existing condition and bringing the new innovative solutions that are more realistic to the nature of local users of Karachi city.
\end{abstract}

Keywords: City traffic, public transportation, buses, passengers, Karachi.

ENGINEERING JOURNAL Volume 18 Issue 1

Received 6 January 2013

Accepted 7 May 2013

Published 14 January 2014

Online at http://www.engj.org/

DOI:10.4186/ej.2014.18.1.55 


\section{Traffic Congestion and Transportation Management}

For the rapid increase in traffic congestion, integrated multimodal transport system is required. The savings to the community in facilitating a shift to public transport can be significant, particularly in urban peak congested conditions. This might be possible through enhancements in service alternatives. Improvements to public transport may be considered through a number of avenues including improving vehicle efficiency, integration of transport modes, reduction of the cost of service, reductions in travel times and in comfort for passengers [1]. Congestion is the measure to find out the optimum characteristics of traffic ciaos while the adaptive measures are also encountered with this scale. Keeping in view the demand orientation, standards are set out with the base line of area requirements. Benchmarks should be identified where measures are to be planned and then short term and long term proposals are highlighted.

\section{Scope of Research Work}

There is the immense need for the system transformation by proper means. The study is designed in a way that number of factors is interlinked and correlated which ultimately segregate the different public transportation problems with their effective measures. The entire scope of work for this study resembles with production of theoretical model related to improved public transportation system. The model might be replicated with the similar city traffic conditions. Almost the metropolitan city of Karachi deals with all type of road users and traffic characteristics environment which in turn useful for majority of the traffic conditions. The model is represented in a manner by taking the related factorable examples of different countries. Not only that similar city of Pakistan, Lahore is also quoted in the model development of urban transportation system. The scope of the study entails with the main public transportation problems of the city with analytical background. With this based on questionnaire survey, recommendations are formulated.

\section{Objectives}

Some of the concerned objectives of this research paper are as follows:

1) Identification of important problems related to public transportation system in Karachi

2) To highlight the root cause of the abrupt network and associated problems with the identification of solutions

3) Development of Public transportation questionnaire survey for community benefits

4) Detailed discussion and analytical findings on the collected data meant for the improvement in public transportation system

5) Validation model of public transportation system with supportive examples of different cities (Literature review) and brief facts \& findings

6) Improvement in the system by clear justification of innovative techniques for example Intelligent Transportation System

\section{Validation Model for Improved Public Transportation System (Literature Review)}

This validation model is presented in a way that it's comparing the realistic features of Karachi city with the identified developed and developing countries. Some factors are directly related with the traffic conditions of Karachi city others are indirectly concerned with the improved infrastructure facilities. The improved facilities might be adopted with the help of detailed interviews from public. In this way, the model ultimately represents both the theoretical perception and practical analysis of the city keeping in mind the system problems.

\subsection{Infrastructure Applications for Different Worldwide Networks}

Road travel time for major collectors is influenced by the road geometrical conditions, traffic control devices like traffic signals, roundabouts. According to Davidson (1978), Akcelik (1991) and Tisato (1991), travel time function has been considered in Australia [2, 3, 4]. Turnbull (1992) indicated over $500 \mathrm{~km}$ of bus lanes throughout Europe accommodating $200 \mathrm{~km}$ in Paris [5]. As per the data of London Transport (1997), proposal is designed to extend the bus lane length up to $500 \mathrm{~km}$ more [6]. Not only that, there are number 
of examples in United States generated the culture of active priority or signal preemption. On the basis of the study of Batz (1986), it was found to have sixteen instances of signal preemption systems in the United States [7]. However bus ways is another important alternative in lower speed environment adjacent to main arterials and collector roads. In this connection two notable examples are in North America, Ottawa and Pittsburg [8]. Some of the recent studies such as Eco North west and Centre for Urban Transportation Research (CUTR) study in the Puget Sound area plugged the empirical data in order to estimate the mode shifts improvements [9].

Due to the higher use of private motorization safety of road users is affected [10], also important the threat featuring quality of human environment $[11,12]$.

\subsection{Contextual Situation Featuring Public Transportation Thailand \& Brazil (Chieng Mai \& Curitiba)}

Chieng Mai is the second city of Thailand, and is located $700 \mathrm{~km}$ north-west of Bangkok. The public transport system in the city comprise of minibuses and conventional bus system like the existing system of Karachi (although the parallel issues in the system are not similar). It presents a situation in which the provision of public transport is almost completely in the hands of mini bus operations. This situation again stands on specifically for the Karachi system because the local transport owners are strong enough and impart with avoidance of enforcement actions taken. The strategies defined in the respective countries should be practiced keeping in view the area considerations. The mini bus service should be such that there prevails no fixed routes, the travelers make use of the service as though it were a taxi, the difference being that sharing the mini bus with other users is common and the fare is at a flat rate for all journeys within the city. The two exceptions to this general principle are the two fixed routes between the city centre and the route specifically designed for universities, schools and colleges (peak hour timings ) [13]. The planning of the system is enhancing with the passage of time but unfortunately Karachi is lacking behind it governing much higher share of population with this city.

The express bus system in Curitiba, Brazil is operated on the reserved bus lane provided along the central part of the structural routes. Present situation is that the express buses should not leave the bus lanes and should just provide a shuttle service up and own the lanes with feeder buses meeting the express buses at interchanges along the length of bus lanes. Bus stops are being provided at intervals of about 800 meters along the length of bus ways and three central terminals are being provided [14]. The discussed practices might be utilized for the city of Karachi as the diversified nature.

\section{Research Methodology}

The research was started with the tentative survey of the public transportation system of Karachi. These include the condition of existing route network, public transport condition, bus stops condition, infrastructure provided etc. Based on the existing condition, a questionnaire survey was done for direct opinions. 100 public interviews are taken for better evaluation. The sample size normally depends on the qualitative data of any plan. It is the common fact that low sample size with improved quality (all entities filled) is better than the high sample size with low quality (with missing elements).

\subsection{Designing of Questionnaire}

The research was specifically molded on the detailed questionnaire designed. The data is collected with different set of people (approximately 100 sample size). The questionnaire is broadly divided in two categories namely personal information and passenger related information. The passenger related information is subdivided into following categories.

1) Mode used

2) Usage of buses

3) Satisfaction from route and fare

4) Satisfaction from seating capacity and management

5) Situations faced in transport service

6) Existence of bus stops and condition

7) Dwell time and shortage of buses 


\section{8) Suggestions for new innovations}

New innovations are discussed with public by giving them the detailed idea of Intelligent Transportation system. Intelligent Transportation system is justified to the persons with its significance, use of technology and engineering measures, application of effective infrastructure, training of ITS and user friendly approaches etc.

\section{Practical Public Transport Condition in Karachi City}

As defined earlier, the public transport condition for the city of Karachi is worsening day by day. Number of factors is depended for this situation. In order to have the clear perspective, some pictorial views are taken for justifications.

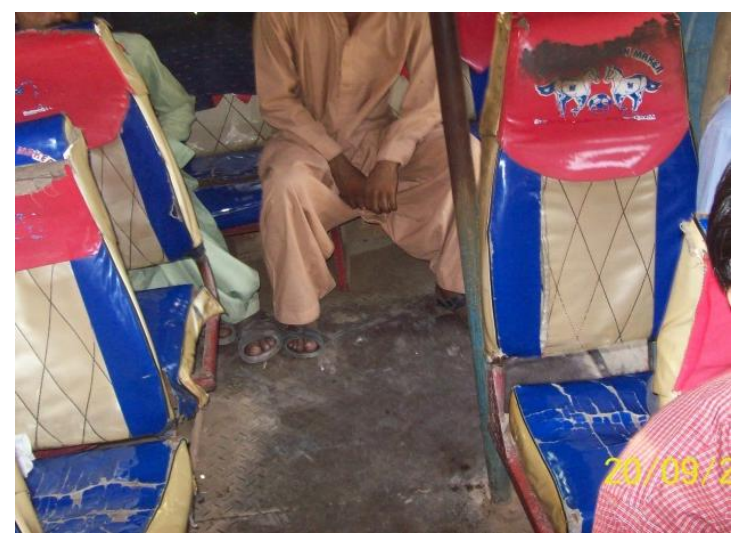

Fig. 1. Miserable condition of buses (Karachi city).

Miserable condition of Mini buses is presented above. For the safe accommodation of journey, comfort of passengers is mandatory. Road users are forced to sit in this environment because of no other option availability. The bus furniture is not satisfactory, even the glass, doors and windows are not quietly maintained by the owner group. This leads to the lack of safety measures implementation not on the road but also off the road environment.

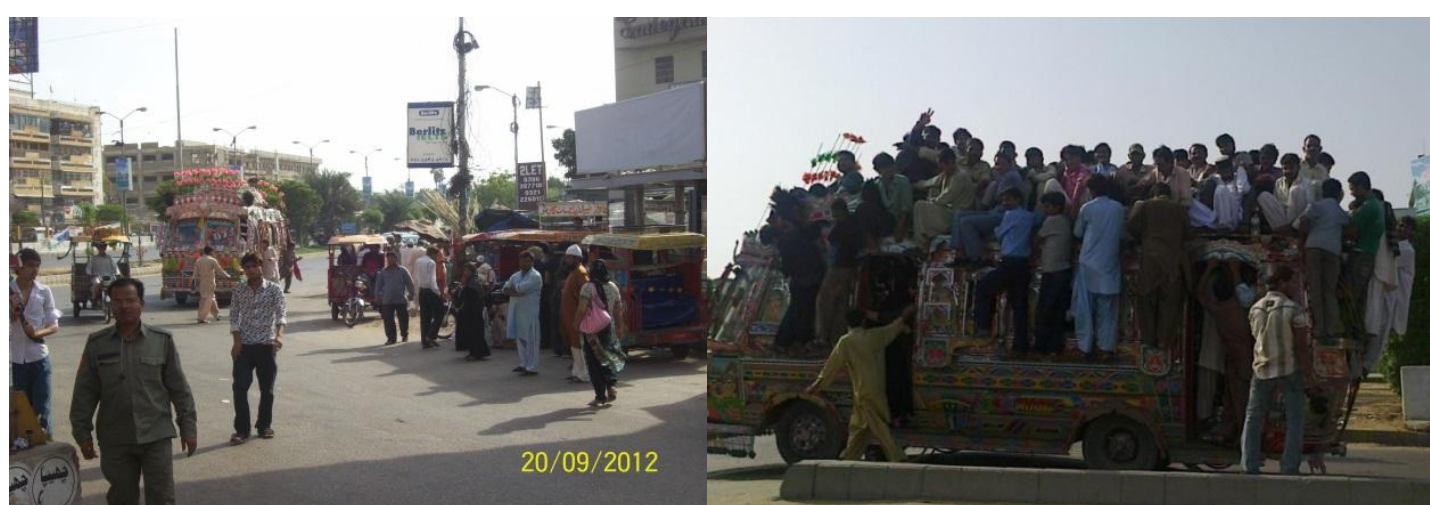

Fig. 2. Encroachments at bus stops (left) and overloading of buses (right).

Two important issues are discussed in the above pictorial views. In the left picture, it is quite evident that buses are not frequently using the designated bus stops whilst the bus stops are totally encroached with the fixed, moveable encroachments and Para transit mode as well. In the right picture, overloading is clearly defined which is hazardous for Pedestrians and Passengers. No ultimate action is taken for these road users while standards should be formulated on the roof top sitting. The present situation also transforming the idea of narrow width walkways because Pedestrians are in trouble in this critical situation. With the passage of time, there is the big increase in the number of buses but the system stand on with the same pattern. It needs to be refurbished and redesigned. 
Regardless of all, several issues including safety and security for buses, management operations, travel network, fare improvement, route redesigning and lack of engineering measures should be incorporated and retackled.

\section{Analytical Facts and Findings}

The findings are detailed analyzed as discussed below. The mode of transport is categorized as Bus, Mini bus, Coach and Wagons. As the collected data shows, almost same percentage of road users are using buses and mini buses while the interview question related to trip generation for the whole day shares the percentage of $50 \%$ (almost half of the collected data) ensuring the use of major two vehicles.
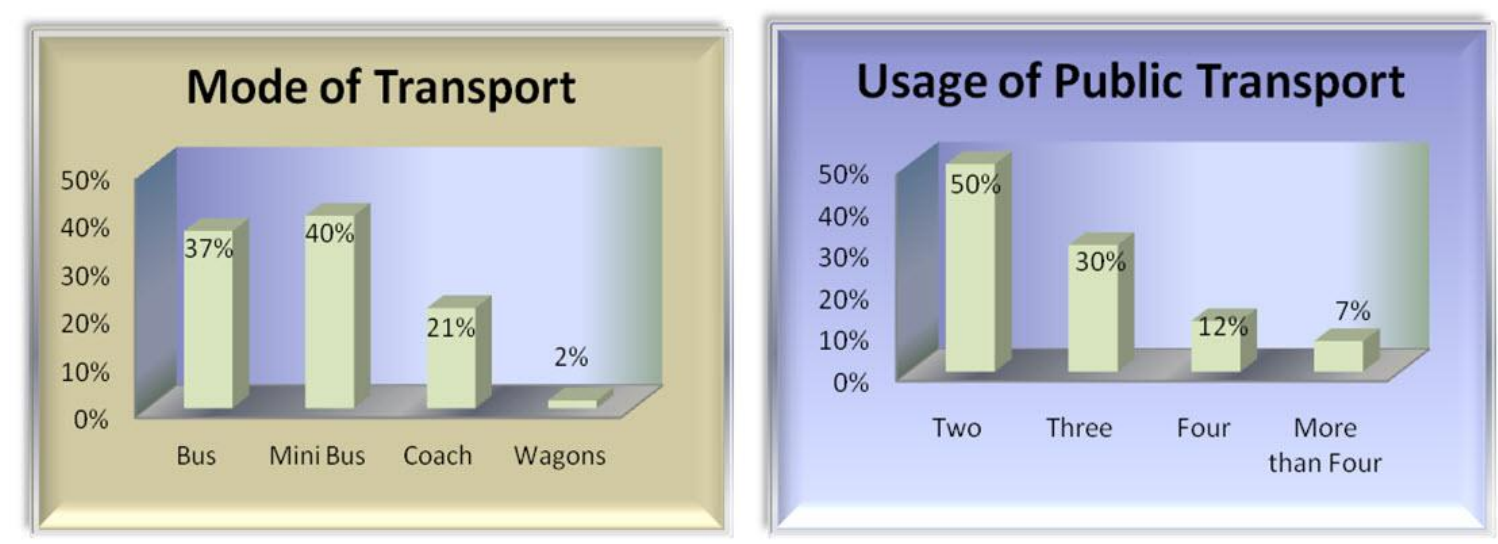

Fig. 3. Graphical representation for mode of transport and usage of public transport.

$40 \%$ road users are willing to use the services of Mini buses with more than $50 \%$ related to working and education purpose of travel. Mini buses routes should be redesigned in order to facilitate the major group. The three percent lap in between the buses and mini buses is due to the inadequate facilities provided in buses although long buses should be prefered for capacity and safety purpose instead of mini buses.
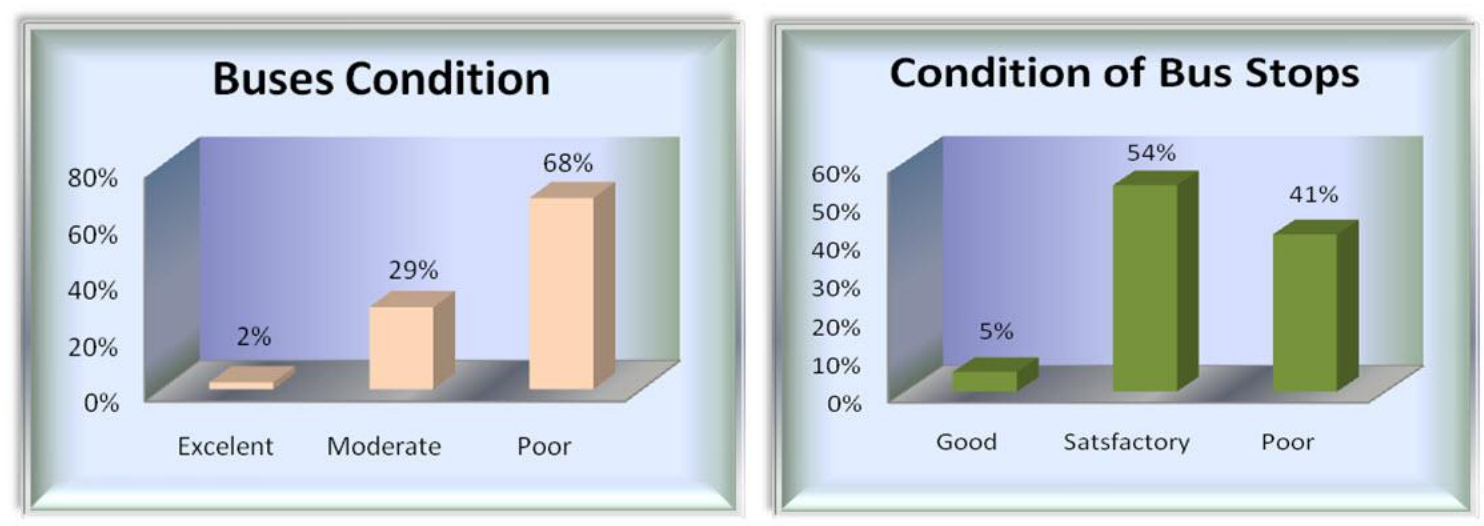

Fig. 4. Graphical representation for condition of buses and bus stops

From the above analyzed data, $68 \%$ respondents agreed on the poor bus conditions including seating arrangement, improper bus operations, bus fleet and bus furniture. While the bus stop which is the ultimate need before entering the buses is also affected, as $54 \%$ and $41 \%$ respondents agreed on the satisfactory and poor bus stop conditions respectively. For the improvement in bus stops private sector should join hands with the public sector and detailed survey strategy should be imposed for having the better capacity of bus stops.

A list of problems in transport service were presented in front of the respondent including Behavior of transporters, Traffic accidents, miserable condition of buses, illegal activities in buses, social issues faced, improper design of the buses, overloading and other factors. The results are quite interesting, almost same 
percentage is observed featuring the miserable condition of the existing buses and illegal activities including snatching and socio economic issues $(16 \%)$. The issues should be tackled by strict Enforcement actions and manipulation of standard practices with policy formulation. Apart from that highest $24 \%$ road users are affected with overloading action leading towards the unfortunate traffic crashes. They might be associated with the human, vehicle or road contributory factors. In response to the improved and innovative modifications, $74 \%$ users are willing to use the Intelligent Transportation System with proper training in order to adjust the discussed problems. Here it is clear that complete and sound knowledge of ITS is provided to the person before asking relevant question. The idea is graphically represented as follows:
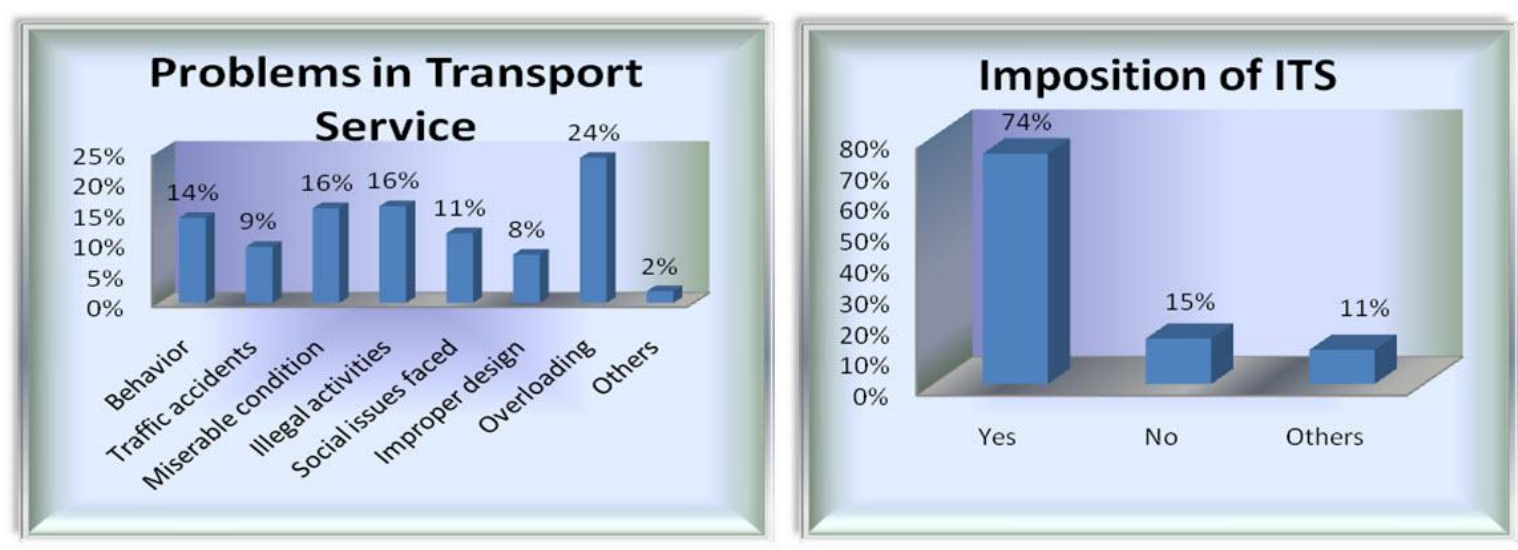

Fig. 5. Graphical representation for transport services and imposition of ITS.

Some other realistic facts drawn from the analyzed results are as follows:

- Only 1\% road users lie in the category of Excellent route condition while $52 \%$ are in the favor of satisfactory condition

- $32 \%$ respondents are not satisfied with the existing fare imposition while $63 \%$ are in the stage of satisfactory

- The analyzed data shows that more than $60 \%$ users are normally take buses for their destinations from any of the place where they want but not form the designated bus stops. This is due to the illegal stops assigned by the owners or absence of bus stops in many of the locations

- It's a good sign that $88 \%$ passengers adopt the practice to walk less than $1 \mathrm{~km}$ for bus stops ensuring the minimum distance between the destination and bus stops

- Interconnected pedestrian bridges with bus stops is promoted in the local public and its also showing from the collected data with the percentage of $84 \%$

- Time saving of the passengers is also another important factor but the percentage of people, waiting for their buses less than 5 minutes is only 7\%. While $68 \%$ respondents lie in the category of 5 to 15 minutes waiting time experienced. More than 15 minutes percentage is $26 \%$

- Highest $48 \%$ shortage of buses is noticed during dark timings (after 8:00 PM)

Within the variety of public transport services, a list of problems is discussed above like behavior, condition of buses and social issues etc. The specific type of transport and problems are shared and merged with respect to the number of respondents as follows: 
Table 1. Mode of transport and situations faced in transport service.

\begin{tabular}{|c|c|c|}
\hline Mode of Transport & Situations faced in transport service & Number of Persons Answer \\
\hline \multirow{8}{*}{ Bus } & Behavior of responsible & 28 \\
\hline & Traffic accidents & 14 \\
\hline & Miserable condition of buses & 30 \\
\hline & Snatching or other illegal activities & 29 \\
\hline & Social issues faced & 25 \\
\hline & Improper bus design & 11 \\
\hline & Overloading of buses & 43 \\
\hline & Others (mention) & 4 \\
\hline \multirow{8}{*}{ Mini Bus } & Behavior of responsible & 31 \\
\hline & Traffic accidents & 20 \\
\hline & Miserable condition of buses & 32 \\
\hline & Snatching or other illegal activities & 35 \\
\hline & Social issues faced & 25 \\
\hline & Improper bus design & 15 \\
\hline & Overloading of buses & 45 \\
\hline & Others (mention) & 3 \\
\hline \multirow{8}{*}{ Coach } & Behavior of responsible & 19 \\
\hline & Traffic accidents & 10 \\
\hline & Miserable condition of buses & 19 \\
\hline & Snatching or other illegal activities & 15 \\
\hline & Social issues faced & 14 \\
\hline & Improper bus design & 9 \\
\hline & Overloading of buses & 26 \\
\hline & Others (mention) & 1 \\
\hline \multirow{8}{*}{ Wagons } & Behavior of responsible & 1 \\
\hline & Traffic accidents & 1 \\
\hline & Miserable condition of buses & 1 \\
\hline & Snatching or other illegal activities & 2 \\
\hline & Social issues faced & 2 \\
\hline & Improper bus design & 1 \\
\hline & Overloading of buses & 2 \\
\hline & Others (mention) & 1 \\
\hline
\end{tabular}

Each problem is identified in relation to the mode of transport. It is dominant form the above table that overloading of public transport is more susceptible to the system. The problem must be solved by the increase in fleet size, enforcement measures or some other technological alternative.

\section{Setting out Example with Model Urban Transport System, Lahore}

For the enhancement of the proposal, model urban transport system Lahore Volvo project is elaborated. The information system for all modes of transport is being collected. The main theme was based on the urban travel pattern falling into three categories [15].

- General information related to house hold research

- Technical operational activities and route network design as in input

- Wider aims of development in relation to role of transport and urban development

The information was adjusted with travelling information, alternatives, motivation and problems of the daily commuters. In this connection, modal split can be easily seen in the picture. It is also emphasized with the average trip frequency. This practice was beneficial for efficient land-use pattern and road requirements for each class of vehicle. Trip demand generated from the analysis is also useful for spatial distribution and alternatives applied. Karachi is also equipped with dense traffic environment. Same type of model study should be done in major corridors for the improvement in Public transportation system. The data which is presented in this research paper might be reorganized and used for future work of modal split assessment. 


\section{Recommendations and Way Forward Approaches}

Based on the analyzed data and survey done following recommendations and major way forwards steps are required:

\section{Technical and Basic Improvements Required}

1) A task force related to engineers, transporters, practitioners and traffic engineers is capable enough to work on community basis for the improvement in Public transportation.

2) The modes of transport that are in practice should be clearly identified in relation to the safety standard policies.

3) Public private partnership programs should be promoted for the improvement actions.

4) While considering any of the matter related to public transport system, balanced should be maintained within the three E's of transportation including Education, Engineering and Enforcement.

5) Computerized fare collection system should be introduced while the average fare should be decided based on the analyzed data.

6) The existing buses condition should be refurnished while the design of buses should be checked by some concerned approved authority.

7) Enforcement is important but when dealt with technological advancement. All the data and actions should be monitored and controlled through surveillance cameras.

8) Minimum bus dwell times should be designed; this could be possible by increasing and introducing the long articulated buses. This not only ensures the safety and capacity but also the removal of traffic congestion.

9) The legislations and government should be proactive while focusing on the solutions. This persists with the strong interaction of all types of stakeholders.

10) Route redesigning is one of the important steps that should be controlled through the calculated strategic applications that are in practiced for developed countries.

11) Para transit modes should be as minimum but to be present in specific amount with quality enhancement. This service is required for the enriched and effective public transport system.

12) Vehicle ownership is another important clause of adverse public transport system. This should be controlled by stringent actions.

\section{Specific Improvements Required on the basis of Analysis}

1) Improvement actions should meant for the buses and mini buses due to more and common percentage in collected data.

2) 2 to 3 buses of nominal range are utilizing by a respondent so safe and reliable journey is mandatory for the user.

3) Bus ways and Transit lane applications should be provided with respect to the purpose of travel. Major travelling accommodates with the working and educational perspectives. Signaling system for entire bus network based on the peak timings might be introduced.

4) Not only the inner condition of the existing buses, but infrastructure should be improved. This solution is justified with the response of persons relying on the satisfactory condition of routes.

5) Roof top sitting on the buses should be strictly prohibited. The data is showing major problem of overloading in almost all modes of public transport.

6) Interconnected pedestrian bridges with bus stops should be promoted as per the justification from data.

7) Alternatively, for the safe accommodation, underpasses for pedestrians and passengers should be constructed.

8) Imposition of Intelligent Transportation System (ITS) with adequate transit network is required. A sufficient percentage of data is willing to initiate the advancements in Public Transportation system.

9) For different group of timings (dawn, daylight, dusk and dark), required number of vehicles should be accommodated. 
10) Fleet size of the buses with proper maintenance should be signified.

11) Maintenance department for all type of buses should be designed and they will be responsible for all types of routine and periodic maintenance works.

12) The measures should be focused mainly on major arterials and collectors. Locals should be on second prior basis.

\section{Conclusion}

Karachi is the densely populated metropolitan city of Pakistan. It consists of all modes of transportation and all type of road users with two prong needs and requirements. According to the registered data of City District Government Karachi, 2005, public transport pertain the share of about 169201 vehicles (registered only) and needs strong considerations. The intercity traffic of this city is becoming unpredictable, different solutions suggested by various concerned authorities are obsolescing one after another. The system needs little alterations based on the requirements of common users. The model presented in the paper must follow with certain limitations of specified area. Management actions formulated are on priority and assembled on the basis of equal treatment actions. The traffic pattern of Karachi city should be correlated with the similar cities of developing countries. In addition to that traffic and transport regulatory authorities in Karachi are responsible for relevant technical approaches of road safety complying this study as a reference or bench mark step. It is quite evident from the research that respondents rely on cheaper, cleaner and mobilized public transport while the task is difficult in Karachi due to rapid growth and change considerations. This study presents public transportation modes operated by the examined metropolitan areas. The results indicate that after availability of public transport in each identified area, the daily commuters still face great hardships due to poor quality of service, substandard and limited vehicles, overcrowding, high fares and clumsy routes. Government has very limited control over these bus operators and in the absence of adequate mega city governance and management system the task is getting complex when it comes to the reduction of negative impacts. An intelligent and smart public transportation framework system (based on the viewpoints of major population) might be helpful in order to decrease the private vehicles. The solutions catered must produce the balance in between the all aspects including technical, user friendly, financial and political issues as well because it is the plight in all around the world to produce best urban transport systems with high levels of political support.

\section{References}

[1] D. Jepson and L. Ferreira, "Assessing travel time impacts of measures to enhance bus operations. Part I: Past evidence and study methodology," Road and Transport Research, vol. 8, no. 4, pp. 41-54, 1999.

[2] K. B. Davidson, "The Theoretical basis of a flow-travel time relationship for use in transportation planning," Australian Road Research, vol. 8, no. 1, pp. 32-35, 1978.

[3] R. Akcelik, "Travel time functions for transport planning purposes: Davidson's function, its timedependent form and an alternative travel time function," Australian Road Research, vol. 21, no. 3, pp. 49-59, 1991.

[4] P. Tisato, "Suggestions for an Improved Davidson Travel Time Function," Australian Road Research, vol. 21, no. 2, pp. 85-100, 1991

[5] K. F. Turnbull, "International high occupancy vehicle facilities," Washington, DC, Transportation Research Record 1360, 1992.

[6] London Transport. (1997). London Transport Internet Site. [Online]. Available: http://www.londontransport.co.uk/facts/fact1_35.html

[7] T. M. Batz, "High occupancy vehicle treatments, impacts, and parameters (a synthesis). Volume 1. Procedures and conclusions," U.S. Dept of Transportation, Report No.FHWA/NJ-86-017-7767, 1986.

[8] C. A. Fuhs, Preferential Lane Treatments for High Occupancy Vebicles (A Synthesis of Highway Practice). Washington, DC: National Academy Press, 1993.

[9] F. Wambalaba, "Public transportation research study: Price Elasticity of rideshare: Commuter fringe benefits for vanpools," Centre for Urban Transportation Research, CUTR, June 2004.

[10] S. Kodukula, "Non-motorized transport in developing countries," 2009.

[11] P. Goodwin, "Simple arithmetic," Transport Policy, vol. 3, pp. 79-80, 1996. 
[12] D. L. Greene and M. Wegener, "Sustainable transport," Journal of Transport Geography, vol. 5, no. 3, pp. 177-190, 1997.

[13] P. R. Fouracre and D. A. C. Maunder, "Public transport in Chieng Mai, Thailand", Transport and Road Research Laboratory, TRRL Supplementary report 285.

[14] P. R. Fouracre, "The development of public transport in Curitiba, Brazil", Transport and Road Research Laboratory, TRRL Supplementary report 197 UC.

[15] Volvo, "Model urban transport system Lahore", 1980. 